\title{
Penilaian Risiko Adanya Total Koliform pada Air Produksi IPA X Menggunakan Metode Failure Mode and Effect Analysis
}

\author{
Bella A. Amanda, Atiek Moesriati, dan Nieke Karnaningroem \\ Jurusan Teknik Lingkungan, Fakultas Teknik Sipil dan Perencanaan, Institut Teknologi Sepuluh \\ Nopember (ITS) \\ Jl. Arief Rahman Hakim, Surabaya 60111 Indonesia \\ e-mail: moesriati@gmail.com
}

\begin{abstract}
Abstrak - Risiko terbesar sistem penyediaan air minum adalah kegagalan menyediakan air minum yang aman bagi masyarakat. Berdasarkan laporan hasil pengujian sampel air produksi IPA X bulan Maret 2016 untuk pemeriksaan parameter wajib diketahui bahwa sampel melebihi baku mutu Permenkes RI No. 492 Tahun 2010 untuk parameter total koliform. Total koliform sebagai indikator pencemaran air oleh patogen menyebabkan air tidak aman dikonsumsi. Proses disinfeksi berperan penting dalam menyisihkan patogen. Kinerjanya dipengaruhi oleh suhu, pH, kekeruhan, dan zat organik. Salah satu cara pengendalian kualitas air produksi melalui pendekatan manajemen risiko menggunakan metode Failure Modes and Effect Analysis (FMEA). Risiko potensial harus terukur agar dapat ditentukan risiko penyebab permasalahan dan tindakan pengurangan risiko yang tepat. Penilaian risiko berdasarkan skala Risk Priority Number (RPN) dijadikan dasar penentuan prioritas tindakan perbaikan. Berdasarkan hasil analisis, risiko kegagalan terbesar yaitu penentuan dosis klor dan zat organik (level risiko tinggi); sisa klor (level risiko sedang); kekeruhan dan pH (level risiko sangat rendah). Usulan perbaikan untuk mengurangi risiko tersebut yaitu dilakukan penentuan dosis klor setiap hari, pengendalian pembentukan disinfectant by products (DBPs) akibat adanya zat organik dalam air dengan menurunkan konsentrasi zat oganik menggunakan granular activated carbon (GAC) atau teknologi aerasi, mengurangi pembentukan DBPs dengan menurunkan dosis disinfektan, menyisihkan DBPs setelah senyawa tersebut terbentuk menggunakan GAC, meningkatkan sisa klor menjadi 0,6 mg/l, melakukan pemantauan kekeruhan dan $\mathrm{pH}$ pada sistem pengoperasian filter.
\end{abstract}

Kata Kunci-FMEA, IPA X, kualitas air produksi, penilaian risiko, $R P N$

\section{PENDAHULUAN}

$\mathrm{P}$ ENYEDIAAN air minum yang sehat, terjangkau, dan aman bagi konsumen salah satunya harus bebas dari mikroba. Berdasarkan data kualitas air baku tahun 2014-2015, parameter yang melebihi baku mutu PP No. 82 Tahun 2001 yaitu parameter Biological Oxygen Demand (BOD), Chemical Oxygen Demand (COD), Dissolved Oxygen, amonia, dan nitrit. Konsentrasi amonia, nitrit, dan zat organik dapat diturunkan melalui serangkaian proses pre-chlorination, koagulasi, flokulasi, pengendapan, filtrasi, dan post-chlorination sehingga memenuhi baku mutu Permenkes RI No. 492 Tahun 2010. Namun berdasarkaan laporan hasil pemeriksaan parameter wajib per 6 bulan air distribusi tahun 2014-2015 diketahui bahwa 2 sampel melebihi baku mutu parameter total koliform dan 1 sampel melebihi baku mutu parameter E.Coli. Selain itu pemeriksaan air produksi pada bulan Maret 2016 diketahui bahwa sampel melebihi baku mutu parameter total koliform. Kehadiran total koliform menjadi indikator pencemaran perairan oleh patogen dan penurunan kualitas air [1]. Air produksi yang didistribusikan kepada masyarakat sudah seharusnya layak konsumsi karena mengacu pada baku mutu Permenkes RI No. 492 Tahun 2010.

Bangunan pengolahan di IPA $\mathrm{X}$ mampu menyisihkan patogen dengan persentase $>99,99 \%$. Proses disinfeksi berperan penting dalam menyisihkan patogen dan menjaga kualitas air selama didistribusikan ke konsumen [2]. Oleh karena itu, penelitian ini difokuskan pada identifikasi risiko penyebab kehadiran total koliform pada air produksi. Pengendalian kualitas air produksi menggunakan pendekatan manajemen risiko untuk mengidentifikasi dan mengukur risikorisiko potensial yang ada agar dapat ditentukan risiko penyebab permasalahan serta tindakan pengurangan risiko yang tepat [3][4]. Penilaian risiko berdasarkan skala Risk Priority Number (RPN) yaitu tingkat frekuensi kejadian (occurrence), tingkat keparahan (severity), dan tingkat deteksi (detection) untuk mencari nilai RPN tertinggi. Nilai RPN dijadikan dasar dalam menentukan prioritas tindakan perbaikan [3].

\section{GAMBARAN UMUM DAERAH PENELITIAN}

Sumber air baku IPA berasal dari Sungai Afvoer yang dicemari oleh limbah domestik dan industri di sekitar aliran sungai. Alur proses pengolahan dapat dilihat pada Gambar 1.

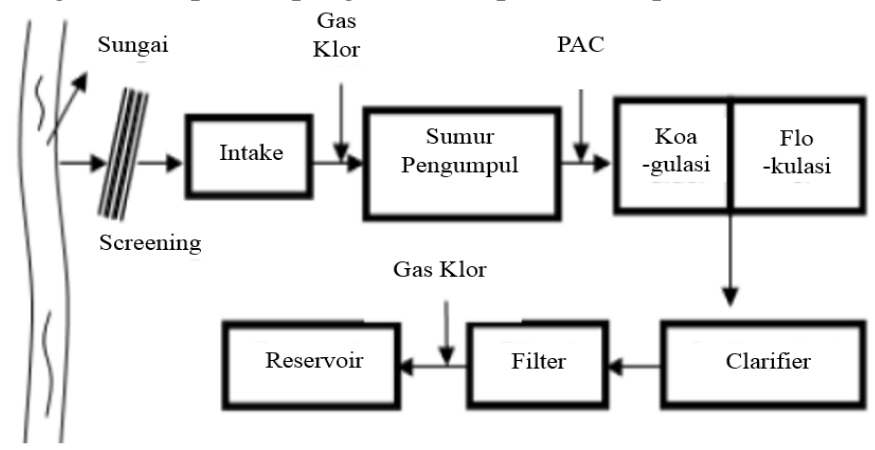

Gambar 1. Alur Proses Pengolahan IPA X

Terdapat 2 buah reservoir untuk menampung air yang akan didistribusikan, reservoir 1 berasal dari air olahan IPA 1 dan IPA 2 serta reservoir 2 berasal dari air olahan IPA 3. Penelitian 
ini difokuskan pada penilaian risiko air produksi IPA 3. Alur proses produksi dapat dilihat pada Gambar 2.

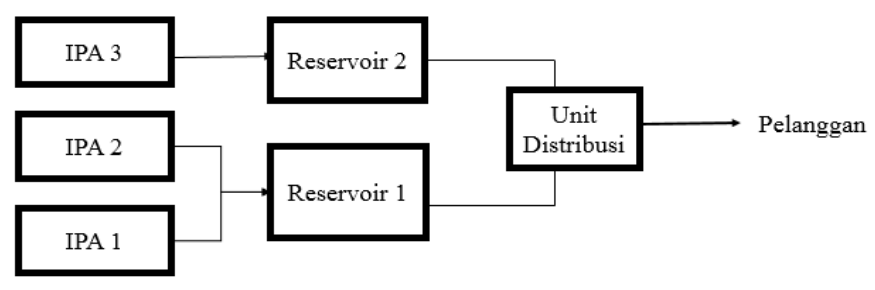

Gambar 2. Alur Proses Produksi IPA X

\section{METODE PENELITIAN}

\section{A. Pengumpulan Data}

Data-data yang digunakan dalam menganalisis kualitas air produksi IPA $\mathrm{X}$ antara lain:

1. Data primer

Observasi dan sampling parameter total koliform, sisa klor, $\mathrm{pH}$, dan kekeruhan, dan zat organik pada air baku, outlet unit clarifier, outlet unit filtrasi, dan inlet reservoir. Analisis sampel air dilakukan di Laboratorium Teknik Lingkungan ITS dan Laboratorium IPA X.

2. Data sekunder

Proses produksi, data kualitas air baku serta air produksi harian dan air distribusi per 6 bulan.

\section{B. Pengolahan Data}

Berdasarkan data kualitas air produksi dibandingkan dengan baku mutu sehingga teridentifikasi permasalahan kehadiran total koliform sebagai risiko penurunan kualitas air produksi. Parameter-parameter terkait risiko kehadiran total koliform dijadikan parameter yang akan dianalisis untuk diidentifikasi akar permasalahannya.

\section{Identifikasi Masalah}

Berdasarkan data- data yang diperoleh maka dapat dibuat fishbone diagram. Diagram tersebut mampu menggambarkan faktor-faktor yang diperkirakan menjadi akar permasalahan.

\section{Analisis Kualitas Air Produksi dengan Metode FMEA}

Identifikasi sumber permasalahan dan pengaruhnya terhadap sistem pengolahan sebagai penyebab kehadiran total koliform pada air produksi. Analisis dilakukan secara "bottom-up", pemeriksaan proses produksi dari kualitas air baku hingga air produksi dengan mempertimbangkan hubungan sebab-akibat. Risiko potensial yang teridentifikasi dinilai menggunakan form severity, occurrence, dan detection. Output dari penilaian tersebut berupa nilai RPN. Semakin tinggi nilai RPN maka risiko kejadian semakin kritis dan membutuhkan tindakan perbaikan. Langkah kerja dari penerapan metode FMEA :

1. Identifikasi risiko potensial terkait parameter kehadiran total koliform pada air produksi dengan melakukan uji kualitas air.

2. Melakukan penilaian severity (), occurent (O), dan detection (D) risiko-risiko potensial yang teridentifikasi.

3. Menghitung nilai RPN dengan persamaan berikut RPN = severity $\mathrm{x}$ occurrence $\mathrm{x}$ detection
4. Menentukan level risiko berdasarkan nilai RPN

5. Memberikan usulan perbaikan dari level risiko tertinggi ke terendah

\section{HASIL PENELITIAN DAN PEMBAHASAN}

\section{A. Hasil Uji Kualitas Air}

Uji kualitas air dilakukan selama 9 hari. Hasil uji kualitas sampel air baku, clarifier, filter, dan air produksi dapat dilihat pada Tabel 1, Tabel 2, Tabel 3, Tabel 4.

Tabel 1.

Kualitas Air Baku Hasil Pengujian di Lapangan

\begin{tabular}{|c|c|c|c|c|}
\hline Waktu sampling & $\mathrm{pH}$ & $\begin{array}{l}\text { Suhu } \\
\left({ }^{\circ} \mathrm{C}\right)\end{array}$ & $\begin{array}{c}\text { Kekeruhan } \\
\text { (NTU) }\end{array}$ & $\begin{array}{l}\text { Zat organik } \\
(\mathrm{mg} / \mathrm{l})\end{array}$ \\
\hline $22 / 03 / 2016$ & 7,1 & 30,8 & 75,9 & 10,33 \\
\hline $23 / 03 / 2016$ & 7,1 & 30 & 100 & 13,26 \\
\hline $24 / 03 / 2016$ & 6,8 & 26,5 & 137 & 13,05 \\
\hline 29/03/2016 & 6,8 & 30,9 & 57 & 11,54 \\
\hline $30 / 03 / 2016$ & 7,3 & 30,8 & 82,4 & 12,98 \\
\hline $31 / 03 / 2016$ & 6,8 & 29,3 & 114 & 15,56 \\
\hline 01/04/2016 & 7,1 & 30,6 & 39,9 & 14,89 \\
\hline $02 / 04 / 2016$ & 7,3 & 29,6 & 52,5 & 8,07 \\
\hline 03/04/2016 & 7,2 & 28,3 & 29,7 & 9,28 \\
\hline Rata-rata & 7,1 & 29,64 & 76,49 & 12,11 \\
\hline
\end{tabular}

Tabel 2.

Kualitas Air Clarifier Hasil Pengujian di Lapangan

\begin{tabular}{ccccccc}
\hline $\begin{array}{c}\text { Waktu } \\
\text { sampling }\end{array}$ & $\mathrm{pH}$ & $\begin{array}{c}\text { Suhu } \\
\left({ }^{\circ} \mathrm{C}\right)\end{array}$ & $\begin{array}{c}\text { Kekeruhan } \\
(\mathrm{NTU})\end{array}$ & $\begin{array}{c}\text { Zat } \\
\text { organik } \\
(\mathrm{mg} / \mathrm{L})\end{array}$ & $\begin{array}{c}\text { Sisa } \\
\text { Klor } \\
(\mathrm{ppm})\end{array}$ & $\begin{array}{c}\text { Total } \\
\text { Kolifor } \\
\mathrm{m}\end{array}$ \\
\hline $22 / 03 / 2016$ & 6,8 & 31,8 & 0,98 & 4,69 & 0,17 & 14 \\
$23 / 03 / 2016$ & 6,9 & 24,2 & 0,72 & 4,00 & 0,17 & 0 \\
$24 / 03 / 2016$ & 6,9 & 30,1 & 1,88 & 4,65 & 0,17 & 33 \\
$29 / 03 / 2016$ & 6,5 & 28,8 & 1,93 & 4,75 & 0,21 & 170 \\
$30 / 03 / 2016$ & 6,7 & 29,7 & 1,27 & 4,85 & 0,13 & 110 \\
$31 / 03 / 2016$ & 6,3 & 29,6 & 1,45 & 4,63 & 0,17 & 300 \\
$01 / 04 / 2016$ & 6,9 & 30,6 & 0,72 & 4,51 & 0,13 & 33 \\
$02 / 04 / 2016$ & 7,2 & 29 & 1,75 & 1,96 & 0,21 & 0 \\
$03 / 04 / 2016$ & 6,9 & 28,9 & 1,02 & 2,19 & 0,26 & 0 \\
Rata-rata & $\mathbf{6 , 8}$ & $\mathbf{2 9 , 1 9}$ & $\mathbf{1 , 3 0}$ & $\mathbf{4 , 0 3}$ & $\mathbf{0 , 1 8}$ & $\mathbf{7 3 , 3 3}$ \\
\hline \hline
\end{tabular}

Tabel 3.

Kualitas Air Filter Hasil Pengujian di Lapangan

\begin{tabular}{ccccccc}
\hline \hline $\begin{array}{c}\text { Waktu } \\
\text { sampling }\end{array}$ & $\mathrm{pH}$ & $\begin{array}{c}\text { Suhu } \\
\left({ }^{\circ} \mathrm{C}\right)\end{array}$ & $\begin{array}{c}\text { Kekeruhan } \\
(\mathrm{NTU})\end{array}$ & $\begin{array}{c}\text { Zat } \\
\text { organik } \\
(\mathrm{mg} / \mathrm{L})\end{array}$ & $\begin{array}{c}\text { Sisa } \\
\text { Klor } \\
(\mathrm{ppm})\end{array}$ & $\begin{array}{c}\text { Total } \\
\text { Koliform }\end{array}$ \\
\hline $22 / 03 / 2016$ & 6,92 & 31,5 & 1,53 & 3,31 & 0,13 & 7 \\
$23 / 03 / 2016$ & 7,00 & 30,3 & 0,65 & 3,51 & 0,13 & 12 \\
$24 / 03 / 2016$ & 6,92 & 27,3 & 0,66 & 3,59 & 0,13 & 17 \\
$29 / 03 / 2016$ & 6,54 & 29,7 & 1,76 & 3,54 & 0,13 & 34 \\
$30 / 03 / 2016$ & 6,77 & 28,3 & 1,76 & 3,58 & 0,13 & 500 \\
$31 / 03 / 2016$ & 6,50 & 29,2 & 0,48 & 3,17 & 0,26 & 300 \\
$01 / 04 / 2016$ & 6,96 & 30,8 & 0,61 & 3,26 & 0,30 & 6 \\
$02 / 04 / 2016$ & 7,15 & 28,8 & 1,23 & 1,92 & 0,13 & 2 \\
$03 / 04 / 2016$ & 7,20 & 29,2 & 1,20 & 2,21 & 0,17 & 4 \\
Rata-rata & $\mathbf{6 , 8 8}$ & $\mathbf{2 9 , 4 6}$ & $\mathbf{1 , 1 0}$ & $\mathbf{3 , 1 2}$ & $\mathbf{0 , 1 7}$ & $\mathbf{9 8}$ \\
\hline \hline
\end{tabular}


Tabel 4.

Kualitas Air Produksi Hasil Pengujian di Lapangan

\begin{tabular}{|c|c|c|c|c|c|c|}
\hline $\begin{array}{c}\text { Waktu } \\
\text { sampling }\end{array}$ & $\overline{\mathrm{pH}}$ & $\begin{array}{l}\text { Suhu } \\
\left({ }^{\circ} \mathrm{C}\right)\end{array}$ & $\begin{array}{c}\text { Kekeruha } \\
\text { n (NTU) }\end{array}$ & $\begin{array}{c}\begin{array}{c}\text { Zat } \\
\text { organik } \\
(\mathrm{mg} / \mathrm{l})\end{array} \\
\end{array}$ & $\begin{array}{c}\text { Sisa } \\
\text { Klor } \\
(\mathrm{ppm})\end{array}$ & Total Koliform \\
\hline $\begin{array}{c}22 / 03 / 201 \\
6\end{array}$ & 7,1 & 31,7 & 1,1 & 3,44 & 0,13 & 23 \\
\hline $\begin{array}{c}23 / 03 / 201 \\
6\end{array}$ & 7,1 & 30,0 & 0,7 & 3,31 & 0,17 & 9 \\
\hline $\begin{array}{c}24 / 03 / 201 \\
6\end{array}$ & 7,2 & 29,9 & 1,1 & 3,46 & 0,21 & 30 \\
\hline $\begin{array}{c}29 / 03 / 201 \\
6\end{array}$ & 6,6 & 31,4 & 2,0 & 3,44 & 0,13 & 220 \\
\hline $\begin{array}{c}30 / 03 / 201 \\
6\end{array}$ & 6,9 & 31,3 & 1,5 & 3,57 & 0,13 & 140 \\
\hline $\begin{array}{c}31 / 03 / 201 \\
6\end{array}$ & 6,8 & 29,8 & 0,7 & 3,23 & 0,26 & 240 \\
\hline $\begin{array}{c}01 / 04 / 201 \\
6\end{array}$ & 7,0 & 29,9 & 0,6 & 3,17 & 0,17 & 140 \\
\hline $\begin{array}{c}02 / 04 / 201 \\
6\end{array}$ & 7,3 & 28,8 & 1,8 & 2,03 & 0,34 & 23 \\
\hline $\begin{array}{c}03 / 04 / 201 \\
6\end{array}$ & 7,3 & 28,4 & 1,2 & 2,24 & 0,17 & 9 \\
\hline Rata-rata & 7,0 & 30,1 & 1,2 & 3,10 & 0,19 & 92,67 \\
\hline
\end{tabular}

\section{B. Penentuan Kriteria Risiko}

Risiko difokuskan pada kejadian yang memengaruhi, menghambat, dan menyebabkan operasional pengolahan air terganggu sehingga menyebabkan adanya total koliform pada air produksi. Risiko tersebut dipengaruhi oleh proses klorinasi. Kinerja klorinasi sendiri sangat dipengaruhi oleh kekeruhan, zat organik, $\mathrm{pH}$, dan sisa klor. Zat organik yang tinggi memicu terbentuknya senyawa DBPs saat bereaksi dengan klor. Kriteria risiko menjadi dasar penilaian risiko sebagai kondisi ideal yang ingin dicapai, dapat dilihat pada Tabel 5 .

Tabel 5.

Kriteria Risiko Adanya Total Koliform pada Air Produksi

\begin{tabular}{clcc}
\hline \hline No & Keterangan & Standar Acuan & Nilai kondisi ideal \\
\hline 1 & Nilai kekeruhan & EPA, 2011 dan Permenkes & $0-1,1 \mathrm{NTU}$ \\
2 & Zat organik & Per/2010 & $0-2,5 \mathrm{mg} / \mathrm{l}$ \\
3 & $\mathrm{pH}$ & Permenkes 492/2010 & $6,5-6,9$ \\
4 & Sisa klor & Permenkes 736/2010 & $0,82-1 \mathrm{ppm}$ \\
& Penentuan dosis & SNI 6778:2008 & Penentuan \\
& klor & & pembubuhan dosis klor \\
\hline \hline
\end{tabular}

\section{Identifikasi Risiko}

Identifikasi risiko merupakan proses penentuan apa, kenapa, dan bagaimana suatu risiko dapat terjadi sehingga suatu sistem dapat dioptimalkan melalui pencegahan atau pengurangan risiko tersebut [5]. Berdasarkan hasil analisis, diperoleh faktorfaktor penyebab risiko yang disusun menggunakan diagram fishbone untuk menentukan akar permasalahan. Berikut fishbone permasalahan hadirnya total koliform pada air produksi dapat dilihat pada Gambar 3.

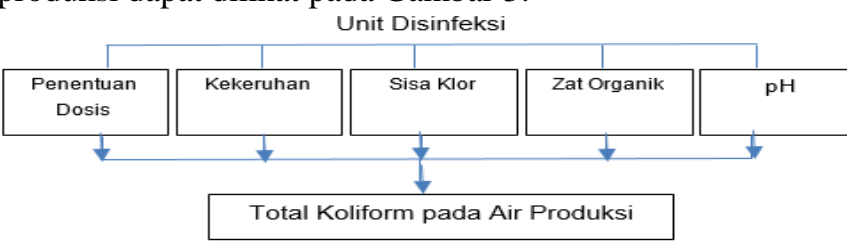

Gambar 3. Analisis Fishbone

Analisis diagram fishbone difokuskan pada penilaian risiko teknis penurunan kinerja unit disinfeksi yang dianggap memiliki dampak besar terhadap risiko adanya total koliform yang menyebabkan air produksi tidak memenuhi baku mutu.
Unit disinfeksi berfungsi sebagai pembubuh bahan kimia untuk mengurangi zat organik pada air baku dan mematikan kuman/organisme setelah melalui pengolahan air minum agar tersedia sisa disinfektan yang dapat mengontrol pertumbuhan patogen selama masa penyimpanan atau distribusi.

\section{Analisis Risiko}

Kriteria penilaian dalam skala 5 untuk memudahkan penetapan interval masing-masing tingkatan sehingga penilaian menjadi lebih sederhana untuk diimplementasikan [6]. Berikut penilaian risiko adanya total koliform pada air produksi.

1) Severity

Severity adalah penilaian terhadap keseriusan dampak yang ditimbulkan dari potensi kegagalan. Semakin besar dampak yang ditimbulkan dari suatu risiko terhadap hadirnya total koliform dalam air produksi, maka nilai severity pun semakin tinggi [7]. Skala besaran risiko dapat dilihat pada Tabel 6, Tabel 7, Tabel 8, Tabel 9, Tabel 10.

Tabel 6.

Skala Besar Risiko Penentuan Dosis Klor

\begin{tabular}{|c|c|c|c|c|}
\hline \multicolumn{5}{|c|}{ "Skala Besar Risiko Penentuan Dosis Klor } \\
\hline 0 & 1 & 2 & 3 & 4 \\
\hline $\begin{array}{c}\text { Sangat } \\
\text { kecil }\end{array}$ & Kecil & Sedang & Besar & Sangat Besar \\
\hline \multicolumn{5}{|c|}{ Skala Kondisi Lingkungan } \\
\hline 5 & 4 & 3 & 2 & 1 \\
\hline $\begin{array}{c}\text { Sangat } \\
\text { Baik }\end{array}$ & Baik & Sedang & Buruk & Sangat Buruk \\
\hline $\begin{array}{c}\text { Melakukan } \\
\text { penentuan } \\
\text { dosis klor } \\
\text { setiap hari }\end{array}$ & $\begin{array}{c}\text { Melakukan } \\
\text { penentuan } \\
\text { dosis klor } \\
3 \text { hari } \\
\text { sekali }\end{array}$ & $\begin{array}{c}\text { Melakukan } \\
\text { penentuan } \\
\text { dosis klor } \\
5 \text { hari } \\
\text { sekali }\end{array}$ & $\begin{array}{c}\text { Melakukan } \\
\text { penentuan dosis } \\
\text { klor } 7 \text { hari sekali }\end{array}$ & $\begin{array}{c}\text { Tidak } \\
\text { melakukan } \\
\text { penentuan } \\
\text { dosis klor }>9 \\
\text { hari }\end{array}$ \\
\hline
\end{tabular}

Tabel 7.

Skala Besar Risiko Sisa Klor

\begin{tabular}{ccccc}
\hline \hline \multicolumn{5}{c}{ Skala Besar Risiko Sisa Klor } \\
\hline 0 & 1 & 2 & 3 & 4 \\
Sangat kecil & Kecil & Sedang & Besar & Sangat Besar \\
\hline \multicolumn{5}{c}{ Skala Kondisi Lingkungan } \\
\hline 5 & 4 & 3 & 2 & 1 \\
Sangat Baik & Baik & Sedang & Buruk & Sangat \\
& $0,59-0,81$ & $0,35-0,58$ & $0,11-0,34$ & Buruk \\
$0,82-1 \mathrm{mg} / 1$ & $\mathrm{mg} / 1$ & $\mathrm{mg} / \mathrm{l}$ & $\mathrm{mg} / \mathrm{l}$ & $>1 \mathrm{mg} / \mathrm{l}$ \\
\hline \hline
\end{tabular}

Tabel 8.

Skala Besar Risiko Kekeruhan

\begin{tabular}{ccccc}
\hline \hline \multicolumn{5}{c}{ Skala Besar Risiko Kekeruhan } \\
\hline 0 & 1 & 2 & 3 & 4 \\
Sangat kecil & Kecil & Sedang & Besar & $\begin{array}{c}\text { Sangat } \\
\text { Besar }\end{array}$ \\
\hline \multicolumn{5}{c}{ Skala Kondisi Lingkungan } \\
\hline 5 & 4 & 3 & 2 & 1 \\
Sangat Baik & Baik & Sedang & Buruk & $\begin{array}{c}\text { Sangat } \\
\text { Buruk }\end{array}$ \\
$0-1,1 \mathrm{NTU}$ & $1,2-2,4 \mathrm{NTU}$ & $2,5-3,7 \mathrm{NTU}$ & $3,8-5 \mathrm{NTU}$ & $>5 \mathrm{NTU}$ \\
\hline \hline
\end{tabular}


Tabel 9.

Skala Besar Risiko $\mathrm{pH}$

\begin{tabular}{ccccc}
\hline \hline \multicolumn{5}{c}{ Skala Besar Risiko $\mathrm{pH}$} \\
\hline 0 & 1 & 2 & 3 & 4 \\
Sangat kecil & Kecil & Sedang & Besar & Sangat Besar \\
\hline \multicolumn{5}{c}{ Skala Kondisi Lingkungan } \\
\hline 5 & 4 & 3 & 2 & 1 \\
Sangat Baik & Baik & Sedang & Buruk & Sangat Buruk \\
pH 6,5-6,9 & $\mathrm{pH} \mathrm{7,0-7,4}$ & $\mathrm{pH} \mathrm{7,5-7,9}$ & $\mathrm{pH} \mathrm{8,0-8,5}$ & $\mathrm{pH}>8,5$ \\
& & & $\mathrm{pH}<6,5$ \\
\hline \hline
\end{tabular}

Tabel 10.

Skala Besar Risiko Zat Organik

\begin{tabular}{|c|c|c|c|c|}
\hline \multicolumn{5}{|c|}{ "Skala Besar Risiko Zat Organik } \\
\hline 0 & 1 & 2 & 3 & 4 \\
\hline Sangat kecil & Kecil & Sedang & Besar & $\begin{array}{l}\text { Sangat } \\
\text { Besar }\end{array}$ \\
\hline \multicolumn{5}{|c|}{ Skala Kondisi Lingkungan } \\
\hline 5 & 4 & 3 & 2 & 1 \\
\hline Sangat Baik & Baik & Sedang & Buruk & $\begin{array}{l}\text { Sangat } \\
\text { Buruk }\end{array}$ \\
\hline $0-2,5 \mathrm{mg} / \mathrm{l}$ & $2,6-5,1 \mathrm{mg} / \mathrm{l}$ & $5,2-7,7 \mathrm{mg} / \mathrm{l}$ & $7,7-10 \mathrm{mg} / \mathrm{l}$ & $>10 \mathrm{mg} / \mathrm{l}$ \\
\hline
\end{tabular}

Semakin besar nilai skala kondisi lingkungan maka semakin kecil nilai risiko kegagalan yang terjadi. Nilai skala kondisi lingkungan 5 sebagai kondisi ideal yang ingin dicapai. Contoh penilaian severity risiko sisa klor sebagai berikut.

Rata-rata range nilai sisa klor $\quad=0,19 \mathrm{mg} / \mathrm{l}$

Skala kondisi lingkungan saat ini $=2$

Skala kondisi lingkungan ideal $=5$

$\begin{aligned} \text { Nilai risiko } & =\frac{\text { Skala kondisi lingkungan ideal-skala kondisi lingkungan saat ini }}{\text { skala kondisi lingkungan ideal }} \times 100 \% \\ & =\frac{5-2}{5} \times 100 \%=60 \%\end{aligned}$

Selanjutnya hasil perhitungan nilai risiko dilihat dalam kriteria severity pada Tabel 11 dan Tabel 12.

Tabel 11.

Kriteria Penentuan Severity

\begin{tabular}{clc}
\hline \hline Range Nilai & \multicolumn{1}{c}{ Kriteria Keseriusan Dampak } & Peringkat \\
\hline$\leq 20 \%$ & $\begin{array}{l}\text { Bentuk kegagalan tidak memiliki pengaruh } \\
\text { Bentuk kegagalan berpengaruh pada kehadiran } \\
\text { total koliform dalam air produksi } \\
\text { Menyebabkan penurunan performa dari fungsi }\end{array}$ & 2 \\
unit, dan berpengaruh terhadap kehadiran total & 3 \\
koliform dalam air produksi & \\
Menyebabkan bahaya yang akan melampaui & & \\
$61-80 \%$ & $\begin{array}{l}\text { standar aturan pemerintah nasional dan } \\
\text { kehadiran total koliform dalam air produksi }\end{array}$ & 4 \\
$>81 \%$ & $\begin{array}{l}\text { Kegagalan menyebabkan air produksi tidak dapat } \\
\text { diterima oleh pelanggan }\end{array}$ & 5 \\
\hline \hline
\end{tabular}

Tabel 12.

Skala Kriteria Keseriusan Kondisi Lingkungan

\begin{tabular}{clc}
\hline \hline Range Nilai & \multicolumn{1}{c}{ Kriteria Kondisi Lingkungann } & Peringkat \\
\hline$\leq 20 \%$ & $\begin{array}{l}\text { Kondisi ideal yang ingin dicapai, memenuhi batas } \\
\text { standar yang ditetapkan }\end{array}$ & 1 \\
$21-40 \%$ & $\begin{array}{l}\text { Air produksi memenuhi batas standar yang } \\
\text { ditetapkan, bisa saja memengaruhi performa unit } \\
\text { disinfeksi }\end{array}$ & 2 \\
$41-60 \%$ & $\begin{array}{l}\text { Air produksi masih memenuhi batas standar yang } \\
\text { ditetapkan, memengaruhi performa unit disinfeksi }\end{array}$ & 3 \\
$61-80 \%$ & $\begin{array}{l}\text { Air produksi memenuhi batas standar yang } \\
\text { ditetapkan, namun dalam batas minimum }\end{array}$ & 4 \\
$>81 \%$ & $\begin{array}{l}\text { Air produksi tidak memenuhi batas standar yang } \\
\text { ditetapkan }\end{array}$ & 5
\end{tabular}

Risiko sisa klor dengan nilai risiko $60 \%$ masuk ke dalam peringkat 3 dengan kriteria keseriusan dampak dapat menyebabkan penurunan performa dari fungsi unit dan berpengaruh terhadap kehadiran total koliform dalam air produksi serta kriteria keseriusan kondisi lingkungan yaitu air produksi masih memenuhi batas standar yang ditetapkan, namun memengaruhi performa unit disinfeksi. Hasil penilaian severity selengkapnya dapat dilihat pada Tabel 13.

Tabel 13.

Nilai Severity Risiko-risiko Kegagalan

\begin{tabular}{ccc}
\hline \hline Jenis Kegagalan & Range Nilai & Peringkat \\
\hline Sisa klor & 0,19 & 3 \\
pH & 6,88 & 1 \\
Zat organik & 12,11 & 4 \\
Kekeruhan & 1,1 & 1 \\
Penentuan dosis klor & Melakukan penentuan dosis klor $<9$ & 4 \\
hari & \\
\hline \hline
\end{tabular}

\section{2) Occurance}

Occurance adalah frekuensi yang diperkirakan dan atau angka kumulatif dari kegagalan yang dapat terjadi [7]. Skala kriteria penentuan occurance dapat dilihat pada Tabel 14.

Tabel 14.

Kriteria Penentuan Occurance

\begin{tabular}{ccc}
\hline \hline Peringkat & Probabilitas Kejadian Risiko & Frekuensi \\
\hline 5 & Sangat sering & 9 kejadian dalam 9 hari \\
4 & Sering & $7-8$ kejadian dalam 9 hari \\
3 & Cukup sering & $5-6$ kejadian dalam 9 hari \\
2 & Kadang-kadang & $3-5$ kejadian dalam 9 hari \\
1 & Jarang & $\leq 2$ kejadian dalam 9 hari \\
\hline \hline
\end{tabular}

Contoh penilaian severity risiko sisa klor sebagai berikut.

$\begin{array}{ll}\text { Rata-rata range sisa klor } & =0,19 \mathrm{mg} / \mathrm{l} \\ \text { Range nilai } & =0,11-0,34 \\ \text { Frekuensi } & =9 \text { kejadian }\end{array}$

Hasil perhitungan nilai risiko dilihat dalam skala probabilitas pada Tabel 14 maka didapatkan risiko sisa klor berada pada peringkat 5 dengan probabilitas kejadian risiko sering terjadi. Hasil penilaian occurance selengkapnya dapat dilihat pada Tabel 15.

Tabel 15.

Nilai occurance risiko-risiko kegagalan

\begin{tabular}{lcc}
\hline \hline \multicolumn{1}{c}{ Jenis Kegagalan } & Frekuensi & Peringkat \\
\hline Sisa klor & 9 kejadian & 5 \\
pH & 3 kejadian & 2 \\
Zat organik & 9 kejadian & 5 \\
Kekeruhan & 4 kejadian & 2 \\
Penentuan Dosis Klor & 9 kejadian & 5 \\
\hline \hline
\end{tabular}

3) Detection

Detection yaitu pengukuran terhadap kemampuan pengendalian risiko kegagalan yang dapat terjadi [7]. Skala kriteria penentuan detection dapat dilihat pada Tabel 16. 
Tabel 16.2

Kriteria penentuan detection

\begin{tabular}{|c|c|c|}
\hline Peringkat & Kriteria Detection & $\begin{array}{c}\text { Berdasarkan } \\
\text { pada } \\
\text { frekuensi } \\
\text { kejadian } \\
\end{array}$ \\
\hline 5 & $\begin{array}{l}\text { Kemungkinan penyebab terjadi sangat tinggi. Metode } \\
\text { pencegahan tidak efektif, penyebab selalu berulang }\end{array}$ & $\begin{array}{l}9 \text { kejadian } \\
\text { dalam } 9 \text { hari }\end{array}$ \\
\hline 4 & $\begin{array}{l}\text { Kemungkinan penyebab terjadi masih tinggi. Metode } \\
\text { pencegahan tidak efektif, penyebab selalu berulang }\end{array}$ & $\begin{array}{l}\text { 7-8 kejadian } \\
\text { dalam } 9 \text { hari }\end{array}$ \\
\hline 3 & $\begin{array}{l}\text { Kemungkinan penyebab terjadi sedang. Metode } \\
\text { pencegahan tidak efektif, penyebab selalu berulang }\end{array}$ & $\begin{array}{l}5-6 \text { kejadian } \\
\text { dalam } 9 \text { hari }\end{array}$ \\
\hline 2 & Kemungkinan penyebab terjadi sangat rendah & 3-5 kejadian \\
\hline 1 & $\begin{array}{l}\text { Metode pencegahan sangat efektif. Tidak ada } \\
\text { kesempatan bahwa penyebab mungkin muncul; }\end{array}$ & $\begin{array}{l}\leq 2 \text { kejadian } \\
\text { dalam } 9 \text { hari }\end{array}$ \\
\hline
\end{tabular}

Semakin besar peringkatnya maka semakin kecil kemampuan metode pengendalian dapat mendeteksi adanya risiko kegagalan mnyebabkan frekuensi risiko kejadian gagal sangat tinggi. Contoh penilaian detection sebagai berikut.
Rata-rata range nilai sisa klor
$=0,19 \mathrm{mg} / \mathrm{l}$
Range nilai
Frekuensi
$=0,11-0,34$
$=9$ kejadian

Selanjutnya hasil perhitungan nilai risiko dilihat dalam range nilai skala kriteria detection berdasarkan pada kejadian risiko kegagalan pada tabel 5.22 lalu didapatkan risiko sisa klor berada pada peringkat 5 dengan metode pengendalian atau pencegahan yang ada tidak efektif untuk mendeteksi adanya risiko kegagalan yang terjadi sehingga kemungkinan penyebab terjadi sangat tinggi dan penyebab selalu berulang. Hasil penilaian detection selengkapnya untuk faktor risiko kegagalan lainnya dapat dilihat pada Tabel 17.

Tabel 17.

Nilai detection risiko-risiko kegagalan

\begin{tabular}{llc}
\hline \hline \multicolumn{1}{c}{ Jenis Kegagalan } & Frekuensi & Peringkat \\
\hline Sisa klor & 9 kejadian & 5 \\
pH & 0 kejadian & 2 \\
Zat organik & 7 kejadian & 5 \\
Kekeruhan & 6 kejadian & 3 \\
Penentuan Dosis Klor & 9 kejadian & 5 \\
\hline \hline
\end{tabular}

\section{E. Penilaian Severity, Occurance, Detection}

Pada dasarnya FMEA merupakan suatu analisis potensipotensi kegagalan yang diwujudkan dalam bentuk angka-angka penilaian (score), dimana score tersebut ditentukan berdasarkan kesepakatan para tim ahli [8].

$\mathrm{RPN}=$ severity $(\mathrm{S}) \times$ occurrence $(\mathrm{O}) \times$ detection $(\mathrm{D})$

Berikut hasil perhitungan angka RPN dari risiko-risiko kegagalan hadirnya total koliform dalam air produksi dapat dilihat pada Tabel 5.24.

Tabel 18.

Perhitungan nilai rpn

\begin{tabular}{llllllll}
\hline \hline No & Unit & $\begin{array}{c}\text { Jenis } \\
\text { kegagalan }\end{array}$ & $\mathrm{S}$ & $\mathrm{O}$ & $\mathrm{D}$ & $\mathrm{RPN}$ & Prioritas \\
\hline \multirow{4}{*}{1} & Sisa klor & 4 & 5 & 5 & 75 & 3 \\
& DH & 1 & 1 & 1 & 4 & 5 \\
& \multirow{3}{*}{ Disinfeksi } & Zat organik & 2 & 4 & 4 & 100 & 2 \\
& & Kekeruhan & 1 & 3 & 3 & 6 & 4 \\
& Penentuan & 4 & 5 & 5 & 100 & 1 \\
\hline \hline
\end{tabular}

Selanjutnya nilai RPN pada Tabel 18. dibaca pada skala penentuan level risiko pada Tabel 19. untuk memudahkan prioritas tindakan perbaikan.
Tabel 18. Perhitungan nilai rpn

\begin{tabular}{cccccccc}
\hline \hline \multirow{2}{*}{ No } & Unit & $\begin{array}{c}\text { Jenis } \\
\text { kegagalan }\end{array}$ & $\mathrm{S}$ & $\mathrm{O}$ & $\mathrm{D}$ & $\mathrm{RPN}$ & Prioritas \\
\hline \multirow{4}{*}{1} & Sisa klor & 4 & 5 & 5 & 75 & 3 \\
& \multirow{4}{*}{ Disinfeksi } & $\mathrm{pH}$ & 1 & 1 & 1 & 4 & 5 \\
& Zat organik & 2 & 4 & 4 & 100 & 2 \\
& & Kekeruhan & 1 & 3 & 3 & 6 & 4 \\
& Penentuan & 4 & 5 & 5 & 100 & 1 \\
\hline \hline
\end{tabular}

Tabel 19.

Skala penentuan level risiko

\begin{tabular}{lc}
\hline \hline Level Risiko & Skala Nilai RPN \\
\hline Sangat tinggi & $101-125$ \\
Tinggi & $76-100$ \\
Sedang & $51-75$ \\
Rendah & $26-50$ \\
Sangat Rendah & $\leq 25$ \\
\hline \hline
\end{tabular}

Berdasarkan Tabel 19. diketahui bahwa kategori level risiko tinggi yaitu penentuan dosis klor dan zat organik; kategori level risiko sedang yaitu sisa klor; kategori level risiko sangat rendah yaitu kekeruhan dan $\mathrm{pH}$. Banyaknya jumlah risiko yang terjadi tidak dapat diperbaiki dalam satu tahap sehingga perlu ditentukan faktor yang paling berisiko dan segera memerlukan tindakan perbaikan. Proses penilaian risiko sangat dibutuhkan untuk menentukan prioritas tindakan perbaikan [3].

\section{F. Usulan Perbaikan}

Melalui identifikasi bagian pengolahan yang memberikan risiko terbesar, penilaian dapat dilakukan untuk mencari solusi mengurangi risiko tersebut [9]. Berikut usulan perbaikan yang dapat menjadi pertimbangan IPA X dari level risiko tertinggi ke risiko terendah.

1) Risiko penentuan dosis klor

Penentuan dosis klorin dilakukan setiap hari dikarenakan kualitas air baku yang akan diolah memiliki karakteristik yang fluktuatif. Adanya total koliform pada air produksi menunjukkan bahwa dosis klor yang diberikan belum cukup untuk menyediakan sisa klor sebagai disinfektan.

2) Risiko zat organik

Selama proses pengolahan air, jika zat organik tidak tersisihkan maka akan bereaksi dengan klorin membentuk precursor organik halogen DBPs seperti trihalometan (THMs) dan asam haloasetik (HAAs) penyebab penurunan efektivitas disinfeksi. Pada opsi pertama, penurunan konsentrasi zat organik dapat dilakukan dengan menerapkan teknologi aerasi atau karbon aktif (granular activated carbon) [10]. Proses aerasi dilakukan pada air baku atau penambahan bangunan karbon aktif (granular activated carbon) setelah unit filtrasi, sebelum proses disinfeksi dilakukan. Pada opsi kedua, menurunkan dosis disinfektan dapat mengurangi pembentukan senyawa DBPs. Konsekuensinya waktu kontak menjadi lebih lama. Dosis yang tinggi mengandung jumlah partikel yang lebih banyak dan rapat dibandingkan dosis yang rendah. Partikel yang susunannya lebih rapat akan lebih sering bertumbukan dibanding dengan partikel yang susunannya renggang sehingga kemungkinan terjadinya reaksi makin besar [11]-[12]. Pada opsi ketiga, dapat diaplikasikan teknologi adsorbsi menggunakan granular activated carbon (GAC) sebelum air produksi didistribusikan ke pelanggan. GAC berfungsi untuk 
menyisihkan partikulat, koloid, dan organik karbon terlarut sehingga DBPs dapat tereduksi dan mikrorganisme patogen berkurang [13].

3) Risiko sisa klor

Pemerintah tidak menetapkan standar untuk efek estetika bau dan rasa pada air, namun dengan menetapkan maksimum konsentrasi sisa disinfektan dapat menghindari dampak fisiologis kesehatan. Mengacu pada Permenkes 736 Tahun 2010 sisa klor yang diijinkan pada air produksi maksimal $1 \mathrm{mg} / \mathrm{l}$ dan sisa klor pada titik terjauh distribusi minimal $0,2 \mathrm{mg} / \mathrm{l}$. Klorinasi pada suatu jaringan distribusi pipa selama pengalirannya mengalami pengurangan (decay) akibat reaksi di dalam fasa bulk air, reaksi dengan dinding pipa dan korosi. Perlu dilakukan permodelan matematika penurunan sisa klor untuk menentukan sisa klor yang harus disediakan pada air produksi dengan persamaan berikut.

$$
\text { In } C e=\text { In } C o-\left(\frac{k}{v}\right) L
$$

dimana:

$\mathrm{Ce}=$ sisa klor pada jarak tertentu

$\mathrm{Co}=$ konsentrasi sisa klor pada $\mathrm{t}=0$

$\mathrm{k}=$ konstanta penurunan

$\mathrm{v}=\operatorname{kecepatan}(\mathrm{m} / \mathrm{s})$

$\mathrm{L}=$ jarak aliran $(\mathrm{m})$

Berdasarkan model matematika tersebut, diketahui bahwa dengan menyediakan sisa klor 0,6 ppm, pada jarak distribusi terjauh 2,99 km, konsentrasi sisa klor memenuhi Permenkes 36 Tahun 2010 yaitu 0,2 ppm. Sisa klor antara 0,2-0,5 ppm dapat menjaga kualitas air dari risiko mikrobiologis.

Peningkatan sisa klor pada air produksi menjadi 0,6 ppm perlu dilakukan untuk menjamin air yang didistribusikan aman dari risiko total koliform. Konsentrasi klor sebagai disinfektan ini masih aman diperuntukkan sebagai air minum. Berikut peta distribusi IPA X terkait dengan sisa klor dapat dilihat pada Gambar 4.

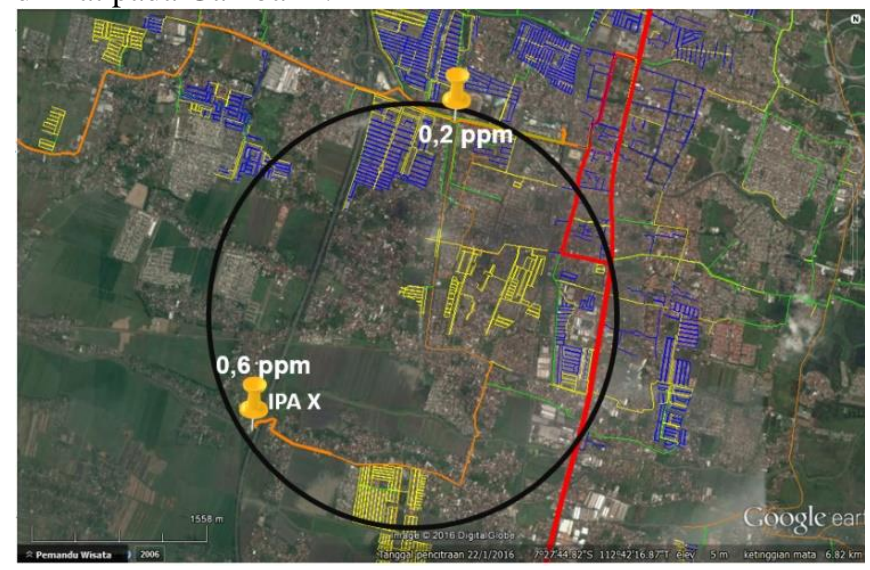

Gambar 4. Peta Jaringan Distribusi IPA X

4) Risiko kekeruhan

Pemantauan sistem pengoperasian dan pencucian filter agar hasil efluen tetap berada pada nilai <1,0 NTU agar proses disinfeksi optimal. Selain itu, perlu dilakukan inventarisasi waktu pencucian filter (backwash), lama waktu backwash, kekeruhan awal (setelah backwash) dan kekeruhan akhir (sebelum backwash). Inventarisasi ini sebagai bagian dari pemantauan proses pengoperasian dan pencucian filter agar kinerja unit disinfeksi optimal.
5) Risiko $\mathrm{pH}$

Pemantauan sistem pengoperasian filter agar kualitas hasil efluen tetap berada dalam rentang $\mathrm{pH}$ 6,5-7,5, dimana $\mathrm{HOCl}$ lebih dominan terbentuk.

\section{KESIMPULAN}

1. Parameter-parameter yang terkait dengan kehadiran total koliform pada air produksi IPA X yaitu kekeruhan, zat organik, $\mathrm{pH}$, dan suhu.

2. Risiko kegagalan terbesar dalam nilai RPN (Risk Priority Number) yaitu penentuan dosis klor dan zat organik (kategori level risiko tinggi); sisa klor (kategori level risiko sedang); kekeruhan dan $\mathrm{pH}$ (kategori level risiko sangat rendah).

3. Usulan perbaikan untuk mengurangi risiko tersebut yaitu dilakukan penentuan dosis klor setiap hari, pengendalian pembentukan DBPs akibat adanya zat organik dalam air dengan menurunkan konsentrasi zat oganik menggunakan GAC atau teknologi aerasi, mengurangi pembentukan DBPs dengan menurunkan dosis disinfektan, menyisihkan DBPs setelah senyawa tersebut terbentuk menggunakan GAC, meningkatkan sisa klor menjadi $0,6 \mathrm{mg} / \mathrm{l}$, melakukan pemantauan sistem pengoperasian filter agar agar hasil efluen tetap berada pada nilai <1,0 NTU dan $\mathrm{pH}$ 6,5-7,5.

\section{UCAPAN TERIMA KASIH}

Penulis mengucapkan terima kasih kepada Direktur Teknik dan Operasional Perusahaan Daerah Air Minum YZ di Jawa Timur, Kepala Produksi, Kepala IPA $\mathrm{X}$, dan petugas Laboratorium PDAM YZ atas bantuannya dalam penyediaan data-data dan fasilitas yang dibutuhkan selama masa pengerjaan penelitian ini.

\section{DAFTAR PUSTAKA}

[1] H. Alang. "Deteksi coliform air PDAM di beberapa kecamatan Kota Makassar", dalam Prosiding Seminar Nasional Mikrobiologi Kesehatan dan Lingkungan, Makassar (2015) 16-20.

[2] N.F. Gray, "Drinking water quality: problems and solution, 2nd edition," UK: Cambridge (2008).

[3] A. Davison, G. Howard, M. Stevens, P. Callan, L. Fewtrell, D. Deere, dan J. Bartram, "Water safety plans managing drinking-water quality from catchment to consumer," Geneva, US: World Health Organisation (2005).

[4] A. Lindhe, "Risk Assessment and Decision Support for Managing Drinking Water Systems," Gothenburg: Chalmers University of Technology (2010).

[5] M.N. Apsari dan N. Karnaningroem, "Analisis risiko dan optimasi kualitas air produksi Instalasi Pengolahan Air Ngagel I," Tesis Program Magister Jurusan Teknik Lingkungan ITS Surabaya (2014).

[6] H. Irawan, "Sepuluh prinsip kepuasan pelanggan," Jakarta: PT Elex Media Komputindo (2002).

[7] A.A. Amanda, "Business continuity plan pada teknologi dan sistem informasi BPR Bank Surya Yudha Banjarnegara," Skripsi Jurusan Sistem Informasi ITS Surabaya (2014).

[8] N. Fitria, "Penilaian risiko pada instalasi pengolahan air limbah (IPAL) rumah sakit dengan metode failure mode and effect analysis (FMEA) : Studi kasus IPAL RSU Dr. Slamet Garut," Skripsi Program Studi Teknik Manajemen Lingkungan ITB Bandung (2009).

[9] A.J. Egerton, "Achieving reliableand cost effective water treatment," Water Science and Technology Vol. 33, No. 2 (1996) 143-149.

[10] Peraturan Menteri Pekerjaan Umum Nomor 18/PRT/M/2007 tentang Penyelenggaraan Pengembangan Sistem Penyediaan Air Minum.

[11] Environmental Protection Agency (EPA), "Water treatment manual: disinfection," Geneva, US: Environmental Protection Agency (2011). 
[12] J.E. Brady, "General chemistry: principles and structure 5th edition," New York: Wiley (1990).

[13] E.A. Farren, "Reducing trihalomethane concentrations by using chloramines as a disinfectant," Worcester: Environmental Engineering Worcester Polytechnic Institute (2003). 